\title{
HUBUNGAN KONDISI OVERCROWDED DENGAN KETEPATAN PELAKSANAAN TRIASE DI INSTALASI GAWAT DARURAT RSU GMIM PANCARAN KASIH MANADO
}

\author{
Vianthy Kundiman \\ Lucky Kumaat \\ Maykel Kiling \\ Program Studi Ilmu Keperawatan Fakultas Kedokteran \\ Universitas Sam Ratulangi \\ Email: vianthy.kundiman@ gmail.com
}

\begin{abstract}
Triage is a patient sorting activity based on the severity of trauma or illness that is carried out immediately in a short time. Overcrowded conditions by patients in the ED due to the incompatibility of patients with the number of overcrowded nurses have an impact on the accuracy implementation of triage in patients aimed at reducing morbidity and mortality. The purpose was to identify the relationship of overcrowded conditions and the accuracy implementation of triage at ED of Pancaran Kasih GMIM Hospital Manado. The design study is analytic survey with cross sectional.Samples 105 respondents with a Non Probability sampling technique namely Consecutive sampling. Results used the Chi square test with a significance level of $95 \%$ so that the value of $p$ value is 0,000 smaller than the significant value of 0.05.Conclusion there is a relationship of overcrowded conditions and the accuracy implementation of the truage at Emergency Department of Pancaran Kasih GMIM Hospital Manado..
\end{abstract}

Keywords: Triage, Overcrowded, Accuracy

\begin{abstract}
Abstrak: Triase merupakan kegiatan pemilahan pasien berdasarkan berat dan ringannya trauma atau penyakit yang diderita yang dilakukan segera dalam waktu yang singkat. Kondisi overcrowded oleh pasien di IGD disebabkan karena tidak sesuainya jumlah pasien dengan jumlah perawat Overcrowded berdampak pada ketepatan pelaksanaan triase pada pasien yang bertujuan menurunkan angka morbiditas dan mortalitas. Tujuan untuk mengetahui hubungan antara kondisi overcrowded dengan ketepatan pelaksanaan triase di IGD RSU GMIM Pancaran Kasih Manado. Metode menggunakan desain penelitian cross sectional study. Sampel terdiri dari 105 responden dengan tehnik pengambilan sampel Non Probability sampling yaitu Consecutive sampling. Hasil menggunakan uji Chi square dengan tingkat kemaknaan 95\% sehingga didapatkan nilai $p$ value yaitu 0,000 lebih kecil dari nilai signifikan 0,05. Kesimpulan terdapat hubungan antara kondisi overcrowded dengan ketepatan pelaksanaan triase di IGD RSU GMIM Pancaran Kasih Manado.
\end{abstract}

Kata Kunci: Triase, Overcrowded, Ketepatan 


\section{PENDAHULUAN}

Instalasi Gawat Darurat (IGD) merupakan salah satu unit rumah sakit yang memberikan pelayanan gawat darurat untuk mencegah terjadinya morbiditas dan meminimalkan terjadinya mortalitas pada semua pasien (Jadmiko, 2014). Peningkatan akses masyarakat memanfaatkan fasilitas IGD sebanding dengan peningkatan jumlah kunjungan pasien sehingga mengakibatkan IGD berada dalam kondisi overcrowded atau kepadatan pasien dengan segala konsekuensinya sekaligus menjadi masalah krisis nasional dan internasional (Ningsih, 2015).

Beberapa tahun terakhir instalasi gawat darurat di United Stated telah melihat peningkatan volume kunjungan pasien sekitar 30 juta pasien per tahun (Department of Health, 2012). Di Indonesia berdasarkan Keputusan Menteri Kesehatan RI (2009) menyatakan data kunjungan masuk pasien ke IGD di Indonesia adalah 4.402.205 pasien (13.3\%) dari total seluruh kunjungan di rumah sakit umum. Terkait dengan data tersebut hasil penelitian yang dilakukan oleh Oroh, dkk (2017) di RSU GMIM Pancaran Kasih Manado menunjukkan dari 80 responden (100\%) dapat diketahui bahwa responden yang dalam kategori overcrowded sebanyak 56 responden $(70.0 \%)$.

Kondisi di dalam IGD yang penuh/overcrowded dengan pasien disebabkan oleh tidak sesuainya jumlah pasien yang datang berkunjung dengan jumlah perawat sehingga mengakibatkan pelayanan di IGD menjadi terhambat bahkan akan menurun kualitasnya (Jadmiko, 2014; Firdaus, 2017). Oleh karena itu pemberian pelayanan kegawatdaruratan memiliki tujuan menurunkan angka morbiditas dan mortalitas sehingga memerlukan kemampuan perawat untuk menggolongkan atau memilah pasien yang membutuhkan pertolongan terlebih dahulu yang disebut triase (Febrina \& Sholehat, 2017). Triase merupakan kegiatan pemilahan pasien yang berdasarkan berat dan ringannya trauma atau penyakit yang diderita serta kecepatan penanganan atau pemindahan pasien (Hosnaniah, 2014). Hasil penelitian Nonutu, dkk (2015) yang dilakukan di IGD RSUP Prof. Dr. R. D. Kandou Manado, didapatkan pelaksanaan triase pada kunjungan pasien dengan kategori jumlah pasien melebihi jumlah perawat pelaksana sebanyak 6 responden $(17,64 \%)$ tepat pelaksanaan triase dan 28 responden $(82,35 \%)$ tidak tepat dalam pelaksaan triase.

Hasil wawancara data awal dengan petugas rekam medik di RSU GMIM Pancaran Kasih Manado pada 18 September 2018, menyatakan jumlah kunjungan IGD pada tiga bulan terakhir yaitu bulan Mei 1.501 pasien, Juni 1.641 pasien, dan Juli 1.547 pasien. Hasil wawancara dengan kepala IGD pada 19 September 2018, menyatakan jumlah tenaga medis yaitu perawat 23 orang yang dibagi 6 orang tiap shiftdantelah memiliki sertifikat pelatihan Bantuan Hidup Dasar (BHD) serta Basic Trauma Cardiac Life Support (BTCLS), jumlah dokter 13 orang yang dibagi satu sampai dua orang tiap shift, terdapat 9 tempat tidur (bed), dan banyaknya pasien yang datang ke IGD rata-rata \pm 50 orang setiap hari serta waktu tinggal pasien di IGD paling lama 2 hari akibat belum tersedianya ruang rawat inap sehingga membuat ruangan IGD menjadi penuh. Berdasarkan latar belakang yang ditemukan, maka peneliti tertarik untuk meneliti hubungan antara kondisi overcrowded dengan ketepatan pelaksanaan triase di Instalasi Gawat Darurat RSU GMIM Pancaran Kasih Manado.

\section{METODE PENELITIAN}

Desain penelitian yang dipilih oleh peneliti adalah survei analitik yaitu mencari korelasi antar variabel dengan menggunakan pendekatan cross sectional. Penelitian ini telah dilaksanakan di Instalasi Gawat Darurat (IGD) RSU GMIM Pancaran Kasih Manado. Waktu penelitian telah dilakukan pada bulan September sampai dengan November 2018. Populasi dalam penelitian ini yaitu seluruh pasien 
yang datang ke IGD RSU GMIM Pancaran Kasih Manado. Jumlah sampel dalam penelitian ini menggunakan rumus slovin dari 1560 orang yaitu 105 orang. Teknik pengambilan sampel yang digunakan peneliti adalah Non probability sampling yaitu Consecutive sampling (Setiadi, 2013).

Instrument penelitian menggunakan lembar observasi kondisi overcrowded didapat dari penelitian Oroh, dkk (2017) tentang hubungan kondisi overcrowded dan pemberian informasi dengan kecemasan keluarga pasien di IGD RSU GMIM Pancaran Kasih Manado dan lembar observasi ketepatan pelaksanaan triase di dapat dari Standar Operasional Prosedur (SOP) Triase RSU GMIM Pancaran Kasih Manado yang terdiri dari 5 prosedur. Perhitungan variabel kondisi overcrowded sebagai berikut: dikatakan overcrowded jika jumlah kunjungan $>9$ orang dan dikatakan tidak overcrowded jika jumlah kunjungan $\leq 9$ orang. Pengukuran variabel ketepatan pelaksanaan triase sebagai berikut: dikatakan tepat jika semua item prosedur dilakukan dan dikatakan tidak tepat jika satu atau lebih item prosedur tidak dilakukan.

Pengolahan data melalui tahap editing, coding, processing, dan cleaning. Dengan analisis univariat dalam penelitian ini adalah kondisi overcrowded di instalasi gawat darurat. Sedangakan analisis bivariat dalam penelitian ini adalah untuk mengetahui hubungan antara variabel independent yaitu kondisi overcrowded dengan variabel dependent yaitu ketepatan pelaksanaan triase di instalasi gawat darurat. Menggunakan uji Chi square dengan tingkat kemaknaan $95 \%(\alpha=\leq 0,05)$.

\section{HASIL dan PEMBAHASAN}

Karakteristik Responden

Tabel 1. Distribusi Sampel Berdasarkan Jenis Kelamin

\begin{tabular}{lcc}
\hline Jenis Kelamin & n & \% \\
\hline Perempuan & 56 & 53,3 \\
Laki-laki & 49 & 46,7 \\
\hline Total & $\mathbf{1 0 5}$ & $\mathbf{1 0 0}$ \\
\hline
\end{tabular}

Sumber: Data Primer 2018

Berdasarkan tabel diatas menunjukkan dari total 105 responden (100\%) yang memiliki jumlah paling banyak berdasarkan jenis kelamin yaitu perempuan sebanyak 56 responden $(53,3 \%)$, sedangkan laki-laki hanya sebanyak 49 responden $(46,7 \%)$. Primanita (2011) menyimpulkan jenis kelamin mempengaruhi persepsi seseorang untuk memanfaatkan fasilitas kesehatan, perempuan lebih banyak melaporkan adanya gejala penyakit dan berkonsultasi dengan dokter dari pada lakilaki.Berdasarkan hasil penelitian di atas dan observasi yang telah dilakukan maka peneliti berasumsi bahwa banyaknya jumlah pengunjung dengan jenis kelamin perempuan karena perempuan lebih mencemaskan situasi dan kondisi dirinya dibanding laki-laki.

Tabel 2. Distribusi Sampel Berdasarkan Usia

\begin{tabular}{lcc}
\hline Kategori Pasien & n & \% \\
\hline Balita & 8 & 7,6 \\
Kanak-kanak & 8 & 7,6 \\
Remaja Awal & 5 & 4,8 \\
Remaja Akhir & 15 & 14,3 \\
Dewasa Awal & 14 & 13,3 \\
Dewasa Akhir & 10 & 9,5 \\
Lansia Awal & 18 & 17,1 \\
Lansia Akhir & 12 & 11,4 \\
Manula & 15 & 14,3 \\
\hline Total & $\mathbf{1 0 5}$ & $\mathbf{1 0 0}$ \\
\hline
\end{tabular}

Sumber: Data Primer 2018

Hasil penelitian menunjukkan dari total 105 responden (100\%) yang paling banyak berdasarkan usia lansia awal sebanyak 18 responden $(17,1 \%)$ dan yang paling sedikit remaja awal yaitu 5 responden 
(4,8\%).Takaendengan (2016) menyatakan bahwa distribusi kasus IGD paling banyak oleh rentang usia 45-64 tahun yang dipengaruhi oleh faktor-faktor seperti jenis penyakit, status kegawatan, tingkat pendidikan, nutrisi dan lainnya. Furwanti (2014) kematangan seseorang secara objektif dapat dilihat dari periode usia yang menunjukkan pengalaman, wawasan, keterampilan dan kemandirian, oleh karena itu usia yang semakin tua akan cenderung memiliki pengalaman yang lebih dalam menyikapi kondisi kesehatannya. Berdasarkan hasil penelitian diatas, jurnal dan teori yang ada maka peneliti berasumsi bahwa semakin tua usia maka seseorang lebih rentan untuk sakit akibat perubahan fisiologis tubuh.

\section{Hasil Analisis Univariat}

Tabel 3. Frekuensi Berdasarkan Tingkat Kondisi Overcrowded di RSU GMIM Pancaran Kasih Manado pada November sampai Desember 2018

\begin{tabular}{lcc}
\hline Variabel & n & \% \\
\hline Overcrowded & 85 & 81 \\
Tidak Overcrowded & 20 & 19 \\
\hline Total & $\mathbf{1 0 5}$ & $\mathbf{1 0 0}$ \\
\hline Sumber: Data Primer 2018 & &
\end{tabular}

Hasil penelitian menunjukkan dari 105 responden $(100 \%)$ yang dalam kondisi overcrowded yaitu 85 responden $(81 \%)$ dan dalam kategori tidak overcrowded yaitu 20 responden (19\%).Penelitian ini sejalan dengan hasil penelitian Firdaus (2017) bahwa kondisi ruangan IGD yang overcrowded atau penuh disebabkan tidak sesuainya jumlah kunjungan pasien dengan jumlah perawat.Jones (2010) berpendapat bahwa pengelolaan petugas di IGD merupakan pekerjaan yang tidak mudah, hal tersebut disebabkan oleh tidak menentunya jumlah dan kondisi pasien yang datang ke IGD, tercukupinya pengaturan rasio perbandingan antara perawat dengan pasien merupakan faktor yang sangat penting agar pelayanan terhadap kebutuhan pasien dapat dilakukan secara optimal.Berdasarkan hasil penelitian diatas dan observasi, peneliti berasumsi bahwa terjadinya kondisi overcrowded di IGD RSU Pancaran Kasih Manado karena jumlah kunjungan pasien yang terus meningkat dan lamanya pasien dpindahkan ke ruang rawat inap maupun dipulangkan.

Tabel 4. Frekuensi Berdasarkan Ketepatan Pelaksanaan Triase di RSU GMIM Pancaran Kasih Manado Pada November sampai Desember 2018

\begin{tabular}{lcc}
\hline Variabel & $\mathbf{n}$ & $\mathbf{\%}$ \\
\hline Tepat & 26 & 24,8 \\
Tidak tepat & 79 & 75,2 \\
\hline Total & $\mathbf{1 0 5}$ & $\mathbf{1 0 0}$ \\
\hline
\end{tabular}

Sumber: Data Primer 2018

Berdasarkan hasil penelitian diatas menunjukkan dari 105 responden (100\%) yang tepat dalam pelaksanaan triase yaitu 26 responden $(41,9 \%)$ dan yang tidak tepat dalam pelaksanaan triase yaitu 79 responden $(58,1 \%)$. Penelitian ini tidak sejalan dengan penelitian yang telah dilakukan oleh Sumarno (2017) yang berjudul hubungan ketepatan pelaksanaan triase dengan tingkat kepuasan keluarga pasien di IGD RSUP. Prof. DR. R. D. Kandou Manado menunjukkan dari 120 responden $(100 \%)$ dalam kategori tepat pelaksanaan triase yaitu 114 responden (95\%) dan tidak tepat sebanyak 6 responden $(5 \%)$.

Ekins dan Morphet (2015) menyatakanketidaktepatan penilaian triase memiliki resiko meningkatkan angka keselamatan pasien dan kualitas dari layanan kesehatan. Berdasarkan hasil penelitian diatas, peneliti berpendapat bahwa pelaksanaan triase yang dominan tidak tepat di IGD RSU GMIM Pancaran Kasih Manado karena banyak jumlah pengunjung pasien yang tidak sesuai dengan jumlah perawat. 
Hasil Analisis Bivariat

Tabel 5. Hubungan Kondisi Overcrowded dengan Ketepatan Pelaksanaan Triase di IGD RSU GMIM Pancaran Kasih Manado pada November sampai Desember 2018

\begin{tabular}{|c|c|c|c|c|c|c|c|}
\hline \multirow{3}{*}{ Kondisi } & \multicolumn{4}{|c|}{$\begin{array}{c}\text { Ketepatan } \\
\text { Pelaksanaan Triase }\end{array}$} & \multicolumn{2}{|c|}{ Total } & \multirow{3}{*}{$\mathbf{P v}$} \\
\hline & \multicolumn{2}{|c|}{ Tepat } & \multicolumn{2}{|c|}{$\begin{array}{l}\text { Tidak } \\
\text { Tepat } \\
\end{array}$} & \multirow[b]{2}{*}{$\mathbf{n}$} & \multirow[b]{2}{*}{$\%$} & \\
\hline & $\mathbf{n}$ & $\%$ & $\mathbf{n}$ & $\%$ & & & \\
\hline Tidak & 11 & 10,5 & 9 & 8,6 & 20 & 19 & \\
\hline $\begin{array}{l}\text { Overcrow } \\
\text { ded }\end{array}$ & 15 & 14,3 & 70 & 66,7 & 85 & 81 & $\mathbf{0 , 0 0 0}$ \\
\hline Total & 26 & 24,8 & 79 & 75,2 & 105 & 100 & \\
\hline
\end{tabular}

Berdasarkan tabel diatas dari 105 responden $(100 \%)$ menunjukkan 85 responden $(81 \%)$ yang berada dalam kategori kondisi overcrowded didapatkan yang paling banyak tidak tepat dalam pelaksanaan triase yaitu 70 responden $(66,7 \%)$. Sedangkan 20 responden $(19 \%)$ yang berada dalam kondisi tidak overcrowded didapatkan yang paling banyak tepat dalam pelaksanaan triase yaitu 11 responden $(10,5 \%)$. Hasil uji hipotesis dengan menggunakan uji Chi square $\left(\mathrm{X}^{2}\right)$ dengan tingkat kepercayaan $95 \%(\alpha=0,05)$, menunjukkan Ho ditolak berarti terdapat hubungan kondisi overcrowded dengan ketepatan pelaksanaan triase di IGD RSU GMIM Pancaran Kasih Manado dimana nila $\mathrm{pv}=0,000$, lebih kecil dari $\alpha=0,05$.

Hasil penelitian ini sejalan dengan penelitian yang dilakukan oleh Nonutu, dkk (2015) yang menunjukkan adanya hubungan yang bermakna antara jumlah kunjungan pasien dengan ketepatan pelaksanaa triase. Penelitian Ainiyah, dkk (2015) yang berjudul analisis faktor pelaksanaan triase di IGD mengatakan bahwa faktor yang mempengaruhi pelaksanaan triase di IGD antara lain faktor pasien yang berhubungan dengan pelaksanaan triase yang optimal, faktor ketenagaan yang baik menunjukkan pelaksanaan triase yang optimal dan faktor perlengkapan yang berhubungan dengan pelaksanaan triase yang optimal.
Dadashzadeh (2013) menyatakan bahwa dalam penelitian kualitatifnya menyatakan bahwa faktor yang mempengaruhi pelaksanaan triase dibagi menjadi 3 kategori yaitu faktor personil (keterampilan dan pengetahuan perawat), faktor pasien dan faktor non personil salah satunya adalah beban kerja. Menurut Ainiyah, Nur (2015) ketersediaan sumber daya merupakan salah satu dukungan yang digunakan perawat dalam memberikan pelayanan keperawatan terhadap pasien secara optimal. Berdasarkan penelitian diatas adanya hubungan antara kondisi overcrowded dengan ketepatan pelaksanaan triase di IGD RSU GMIM Pancaran Kasih lebih dominan pelaksanaan triase tidak tepat disaat kondisi overcrowded, maka peneliti berasumsi tidak sesuainya jumlah perawat dengan jumlah kunjungan pasien yang terus meningkat dan tuntutan pasien yang ingin mendapatkan prioritas pelayanan utama yang tidak sesuai dengan tingkat kegawatan sesuai degan Standar operasional prosedur (SOP). Pasien yang datang paling banyak berada di triase urgent (kuning) dan non urgent (hijau), namun sering tidak diberikan pelayanansesuai dengan sistem triase tersebut.

\section{SIMPULAN}

Berdasarkan hasil penelitian dan pembahasan mengenai hubungan kondisi overcrowded dengan ketepatan pelaksanaan triase di IGD RSU GMIM Pancaran Kasih Manado makadapat disimpulkan sebagian besar pengunjung IGD RSU GMIM Pancaran Kasih Manado berdasarkan jenis kelamin yaitu jenis kelamin perempuan dan berdasarkan usia yaitu usia lansia awal. Sebagian besar kondisi di IGD RSU GMIM Pancaran Kasih Manado berada dalam kategori overcrowded. Ketepatan pelaksanaan triase di IGD RSU GMIM Pancaran Kasih Manado paling banyak tidak tepat dilaksanakan.Terdapat hubungan antara kondisi overcrowded dengan ketepatan pelaksanaan triase di IGD RSU GMIM Pancaran Kasih Manado 


\section{DAFTAR PUSTAKA}

Ainiyah, N., Ahsan dan M. Fathoni.. (2015).Analisis Faktor Pelaksanaan Triage Di Instalasi Gawat Darurat.Malang: Prodi Magister Keperawatan Peminatan Gawat Darurat FK Universitas Brawijaya. Ners Journal Volume 10 Nomor 1 https://www.researchgate.net/publicat ion/32723720The_Factors_Associate d_with_The_Triage_Implementation _in_Emergency_Department Diakses pada tanggal 8 September 2018 pukul 18.00 WITA

Dadashzadeh, A., Abdolahzadeh, F., Rahmani, A., \& Ghojazadeh, M. (2014). Factors affecting triage decision-making from the viewpoints of emergency department staff in Tabriz hospitals, doi 6(4), 261-266.

Department Of Health. (2012). A\&E attendances. Department Of Health

Ekins \& Morphet. (2015). The accuracy and consistency of rural, remote and outpost triage nurse decision making in one Western Australia Country Health Service Region. Australasian Emergency Nursing Journal Vol 18, Issue 4, page 227-223, 2015.

Febrina, W dan I. Sholehat. (2017). Experience Of Nurse Associate To Implement Triage In Emergency Room Installation.Sumatera Barat: Program Studi Keperawatan Stikes Bukittinggi. Jurnal Endurance http://ejournal.kopertis10.or.id/index. php/endurance/article/viewFile/2579/ 932 Diakses pada tanggal 5 September 2018 pukul 16.30 WITA

Firdaus, M. 2017. Penerapan ATS Terhadap Waiting Time Klien Di IGD RSUD Ngudi Waluyo Wlingi Bitar. Prodi D3 Keperawatan STIKes Majapahit Mojokerto. Prosiding Seminar Nasional Hasil Penelitian Dan Pengabdian Masyarakat (1)-2017.
Diakses pada tanggal 29 Oktober 2018http://ejurnalp2m.stikesmajapahi tmojokerto.ac.id/index.php/publikasi _stikes_majapahit/article/viewFile/21 9/192

Furwanti, E. (2014). Gambaran Tingkat Kecemasan Pasien di Instalasi Gawat Darurat RSUD Panembahan Senopati Bantul: Yogyakarta. Jurnal Universitas Muhamadiyah

Garbez, A. R., Carrieri-kohlman, V., Stotts, N., Chan, G., Neighbor, M., \& Francisco, S. (2011). Factors Influencing Patient Assignment to Level 2 and Level 3 Within the 5Level ESI Triage System. YMEN, 37(6), 526-532. http://doi.org/10.1016/j.jen.2010.07.0 10

Hosnaniah, Jazilahtul. (2014).Pelaksanaan Triage Unit Gawat Darurat Rumah Sakit Reksa Waluya Kota Mojokerto. KTI D3 Keperawatanhttp://repository.poltekk esmajapait.ac.id Diakses pada tanggal 5 September 2018 pukul 18.00 WITA

Jadmiko, Arief W. (2017). Pengetahuan Dan Kecerdasan Emosional Terhadap Manajemen Nyeri Di Instalasi Gawat Darurat.Surakarta: Program Studi Ilmu Keperawatan Universitas Muhammadiyah Surakarta. Jurnal Riset

Kesehatanhttp://ejournal.poltekkessmg.ac.id/ojs/index.php/jrk/article/vi ew/1208 Diakses pada tanggal 7 September 2018 pukul 15.00 WITA

Jansen, MA. (2011). Adherence to The Guidline Triage in Emergency Departments: A Survey of Dutch Emergency Departments. J Clin Nurs, 20(17-18), 2458-2468

Keputusan Menteri Kesehatan Republik Indonesia Nomor 856/Menkes/SK/IX/2009 Tentang Standar Pelayanan Instalasi Gawat 
Darurat Rumah Sakit. http://sardjito.co.id/sardjitowp/wpcontent/uploads/2015/12/kepmenkes856-thn-2009-standar-IGD.pdf

Diakses pada tanggal 5 September 2018 pukul 15.30 WITA

Ningsih, Kartikawati D. (2015). Overcrowding Patient And Improving Emergency Patient Flow In Emergency Department: A Literature Review. Malang: Jurusan Keperawatan Fakultas Kedokteran Universitas Brawijaya Malang. Jurnal Ilmu

Keperawatanhttp://jik.ub.ac.id/index. php/jik/article/download/43/62.

Diakses tanggal 5 September 2018 pukul 19.00 WITA

Nonutu, P.,Mulyadi, dan R.Hamel. (2015).Hubungan Jumlah Kunjungan Pasien Dengan Ketepatan Pelaksanaan Triase Di Instalasi Gawat Darurat RSUP Pof. DR. R. D. Kandou. Manado: Program Studi Ilmu Keperawatan Universitas Sam Ratulangi. Ejournal Keperawatan (eKp) Vol.3(2), p.45https://ejournal.unsrat.ac.id/index.ph p/jkp/article/view/8092 /7653 Diakses pada tanggal 5 September 2018 pukul 17.00 WITA

Oroh,A., Mulyadi, dan R.Malara. (2017). Hubungan Antara Kondisi Overcrowded Dan Pemberian Informasi Dengan Kecemasan Keluarga Pasien Di Instalasi Gawat Darurat Rumah Sakit Pancaran Kasih GMIM Manado. Manado: Program Studi Ilmu Keperawatan Fakultas Kedokteran Universitas Sam Ratulangi. Ejournal Keperawatan (e$K p)$ Vol. 5(1)https://ejournal.unsrat.ac.id/index .php/jkp/article/view/14889/14453 Diakses tanggal 5 September $\$ 4.00$ WITA
Primanita, Ahdiah.2011.Hubungan Antara Persepsi Tentang Sakit dengan Pemanfaatan Pelayanan Kesehatan Oleh Peserta Jaminan Kesehatan Masyarakat Di Puskesmas Gunungpati Kota Semarang https://lib.unnes.ac.id/5819/1/7564.pd $\mathrm{f}$

PSIK FK UNSRAT. (2018). Panduan Penulisan Tugas Akhir Mahasiswa

Setiadi. (2013). Konsep dan Praktik Penulisan Riset Keperawatan. Yogyakarta: Graha Ilmu

Sumarno, M., Ismanto, A., dan Y.Bataha. (2017).Hubungan Ketepatan Pelaksanaan Triase Dengan Tingkat Kepuasan Keluarga Pasien Di Instalasi Gawat Darurat RSUP. Prof. DR. R. D. Kandou. Manado: Program Studiilmu Keperawatan Universitas Sam Ratulangi. Ejournal Keperawatan (e-Kp) Vol.5(1), p. 3 https://ejournal.unsrat.ac.id/index.php /jkp/article/view/15896/15409

Diakses pada tanggal 7 September 2018 pukul 20.15 WITA

Takaendengan, D. (2016). Profil 10 Besar Kasus Di Instalasi Gawat Darurat Bedah RSUP. Prof. R. D. Kandou Periode Januari-Desember 2015. Jurnal E-Clinic. https://ejournal.unsrat.ac.id/index.ph p/eclinic/article/view/14567/14139 